\title{
Measurements of Transitional and Turbulent Flow in a Randomly Packed Bed of Spheres with Particle Image Velocimetry
}

\author{
Shervin Khayamyan ${ }^{1}$ (D) T. Staffan Lundström ${ }^{1}$ • \\ J. Gunnar I. Hellström ${ }^{1}$ • Per Gren ${ }^{1}$ • Henrik Lycksam ${ }^{1}$
}

Received: 24 May 2016 / Accepted: 7 October 2016/ Published online: 9 November 2016

(C) The Author(s) 2016. This article is published with open access at Springerlink.com

\begin{abstract}
Particle image velocimetry (PIV) has been used to investigate transitional and turbulent flow in a randomly packed bed of mono-sized transparent spheres at particle Reynolds number, $20<R e_{\mathrm{p}}<3220$. The refractive index of the liquid is matched with the spheres to provide optical access to the flow within the bed without distortions. Integrated pressure drop data yield that Darcy law is valid at $R e_{\mathrm{p}} \approx 80$. The PIV measurements show that the velocity fluctuations increase and that the time-averaged velocity distribution start to change at lower $R e_{\mathrm{p}}$. The probability for relatively low and high velocities decreases with $R e_{\mathrm{p}}$ and recirculation zones that appear in inertia dominated flows are suppressed by the turbulent flow at higher $R e_{\mathrm{p}}$. Hence there is a maximum of recirculation at about $R e_{\mathrm{p}} \approx 400$. Finally, statistical analysis of the spatial distribution of time-averaged velocities shows that the velocity distribution is clearly and weakly self-similar with respect to $R e_{\mathrm{p}}$ for turbulent and laminar flow, respectively.
\end{abstract}

Keywords Porous media $\cdot$ Randomly packed bed $\cdot$ 2D-PIV $\cdot$ Refractive index matched $($ RIM ) $\cdot$ Velocity statistics $\cdot$ Laminar and turbulent flow and recirculation zones

\section{Introduction}

Fluid flow through porous media can be recognized in numerous natural processes (Bear 1972) such as ground water flows (Das et al. 2015), capillary flows in plants and flow in human organs and muscles as well as in many industrial process (Hlushkou and Tallarek 2006) like paper making, making of fiber boards, composites manufacturing (Odenberger et al. 2004; Andersson et al. 2005; Pettersson et al. 2007; Aitomäki et al. 2016) filtering, drying of iron ore pellets (Ljung et al. 2011, 2012) and impregnation of wood, just to mention a few relevant cases. Regardless of the importance of porous media flow and the amount of research that has

T. Staffan Lundström

staffan.lundstrom@1tu.se

1 Division of Fluid and Experimental Mechanics, Luleå University of Technology, 97187 Luleå, Sweden 
been carried out to explore it, understanding of some key topics is lacking. One of these topics is the detailed information about transitional mechanisms between different flow regimes, Stokes flow, inertia dominated flow and turbulent flow, and the alteration of the velocity characteristics between each regime. The traditional approach to handle flow within porous media is to measure its global parameters such as overall pressure drop and longitudinal and transvers dispersion (Dixon and Cresswell 1986; Ergun 1952; Gunn 1987). This will give empirical correlations that can be used to estimate the behavior of porous media and to design special industrial cases such as packed bed reactors (Andrigo et al. 1999; Eigenberger 1992). The mathematical set of equations that can be used to provide comprehensive understanding of physical phenomena in a porous bed can also be derived from the Reynolds-averaged Navier-Stokes (RANS) equations according to de Pedras and Lemos (2001):

(a) Time averaging the volume-averaged equations or the general macroscopic or transport equations (Antohe and Lage 1997; Getachew et al. 2000; Lee et al. 1987; Wang and Takle 1995).

(b) Volume averaging the time-averaged Reynolds-averaged equations (Masuoka and Takatsu 1996; Nakayama and Kuwahara 1999; Kuwahara et al. 1998).

(c) A double-decomposition method since the order of volume and time averaging is immaterial (Pedras and Lemos 2000, 2001).

All these models need to be validated against experiments. A comprehensive investigation of the flow at the pore level may result in more sophisticated models with heterogeneous distributions of variables instead of the common assumption of homogeneous profiles (Andrigo et al. 1999; Eigenberger 1992). To reveal the detailed flow within porous media, the pore level flow has been modelled theoretically and numerically (Geller and Hunt 1993; Hill et al. 2001; Powers et al. 1994; Payatakes 1982; Hellström et al. 2010; Jourak et al. 2013, 2014; Fabricius et al. 2016; Burström et al. 2016). There is also some experimental work on the detailed scale. It is, for instance, clarified that the flow in an individual pore can be greatly influenced by the flow condition of neighboring pores (Khayamyan et al. 2014; Khayamyan and Lundström 2015). These studies were performed on parallel tubes and with detailed measurements of the flow rate and pressure fluctuations. Tomographic and optical techniques can provide additional experimental information about flow field dynamic in porous beds. Tomographic techniques include Magnetic Resonance Imaging (MRI) (Baldwin et al. 1996; Sederman et al. 1998; Ogawa et al. 2001; Suekane et al. 2003), Emission Tomography (PET) (Khalili et al. 1998), NMR imaging (Baldwin et al. 1996; Johns and Gladden 1999), gamma attenuation (Imhoff et al. 1994) and X-ray tomography (Imhoff et al. 1996). The drawbacks of these techniques are rather expensive test facilities and generally poor spatial and temporal resolution, (Chang and Watson 1999; Gladden et al. 2006). The latter is continuously improving and the techniques can be viable in the future. In contrast to tomographic techniques like MRI or NMR imaging, the relative simplicity and low cost of optical techniques such as particle image velocimetry (PIV) and particle tracking velocimetry (PTV) make them attractive. However, optical techniques in porous media require all phases be transparent refractive index-matched (RIM) materials. This limits the range of materials that can be used but it still makes these techniques powerful for generic studies of the flow in porous beds with PTV (Johnston et al. 1975; Stephenson and Stewart 1986; Saleh et al. 1992; Northrup et al. 1993; Peurrung et al. 1995; Moroni et al. 2001; Huang et al. 2008; Lachhab et al. 2008), PIV (Patil and Liburdy 2013) and Laser Doppler Anemometry (Yarlagadda and Yoganathan 1989). PIV require the flow to be seeded with a relatively large number of particles (Raffel 2007; Westerweel 1997). Two separate images of seeding particles can reveal the spatial displacement of patterns of particles or equivalently the instantaneous planar velocity field 
(Adrian 1984, 1991). This method of measurement results in a Eulerian highly resolved flow field. With PTV each seeding particle is traced and a Lagrangian flow field is obtained that contains less information about each point in the field as compared to PIV. As example of results with PTV Northrup et al. (1993) found evidence of inter pore mixing within porous media at $R e_{\mathrm{p}}<1$; PIV measurements in (Patil and Liburdy 2013) yield that at $R e_{\mathrm{p}} \approx 4$ the spatial velocity variance increase when comparing the center plane data versus using data across the entire bed and Lachhab et al. (2008) showed with PTV that velocity has a lognormal distribution in space for $R e_{\mathrm{p}}<1$ and Stephenson and Stewart (1986) found that the latter velocity reaches its global maximum and minimum at distances near 0.2 and $0.5 D_{p}$ from the wall for $5<R e_{\mathrm{p}}<250$.

In the present study, PIV measurements within a randomly packed bed of spheres at $20 \leq R e_{\mathrm{p}} \leq 3220$ are presented. The range covers the higher limit of what can be seen as a Darcian flow to a fully turbulent flow. The only ones that, to the authors best knowledge, have reported similar studies before are (Patil and Liburdy 2013). While (Patil and Liburdy 2013) focus on detailed measurement of turbulent quantities in rather small areas yielding interesting results, such as the pore turbulence characteristics are similar from pore to pore, we here study larger areas and emphasis on time-averaged quantities. The size of the porous bed and the lower range of Reynolds numbers is also larger in this study. The measurements were done with an index-matched fluid and results are presented from five relatively large planes directed along the flow. The characteristic of the fluid flow within the bed is investigated from velocity plots as well as with the normalized probability distribution function (NPDF) of time-averaged velocity components. The results are compared to the overall pressure drop along the bed and with results from the literature.

\section{Experimental Setup}

The experimental setup used to measure the velocity field with PIV within a refractive indexmatched porous bed is shown in Fig. 1. The studied packed bed is made from a randomly packing of Plexiglas (PMMA) spherical particles with a diameter $D_{p}=12.7 \mathrm{~mm}$. These spheres were purchased from Precision Plastic Ball Co., https://www.PrecisionPlasticBall. com. The bed has a square cross section of $100 \times 100 \mathrm{~mm}^{2}$ and its length is $310 \mathrm{~mm}$. The bed width to particle diameter ratio is consequently about 8 , which is about two times larger than the bed width to particle diameter ratio of the bed used by (Patil and Liburdy 2013) in a similar setup. This is large enough to avoid major effects in the mid-plane of channeling near the confining walls on bed overall porosity and permeability (Chu and $\mathrm{Ng} \mathrm{1989).} \mathrm{It} \mathrm{must,}$ however, be noticed that the walls will affect the magnitude of the overall permeability and the porosity distribution. The bed overall porosity $\varphi$ being the ratio of void volume to bed volume is about 0.414 from direct geometrical calculations. The PIV measurements were taken in five planes directed along the main flow. The planes are evenly distributed from the mid-section to half-way between the mid-section and one of the side walls. The fluid is circulated in a closed loop with a centrifugal pump, Tapflo HTM15PP, from an atmospheric pressure storage tank where the temperature of the fluid is regulated and kept at $20 \pm 0.1^{\circ} \mathrm{C}$ with a temperature control unit. The fluid is pumped through an electromagnetic flowmeter from ABB, ProcessMaster FEP300, to the Plexiglas box and finally back to the storage tank in a completely closed system. To ensure constant conditions during the measurement also the absolute pressure at the inlet to the Plexiglas box was monitored with a pressure transducer 


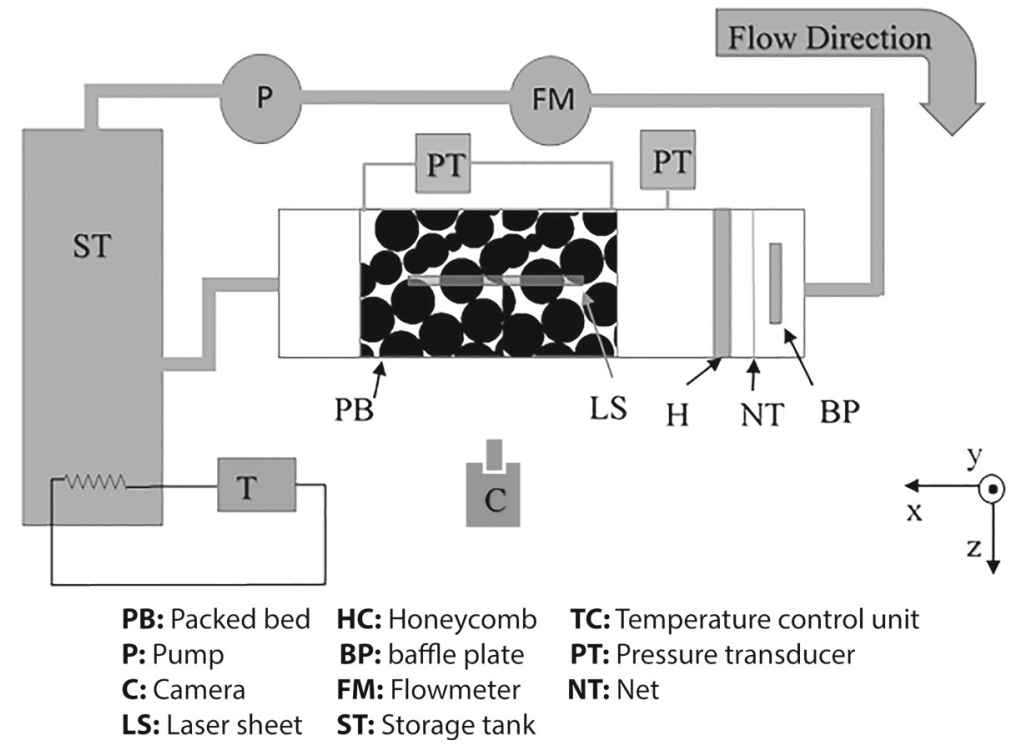

Fig. 1 Schematic of the experimental setup

from General Electric, GE PTX5012. In addition, the pressure difference over the porous bed was recorded with the same type of pressure transducers.

As already mentioned, the Plexiglas box is longer than the bed so that the flow entering and leaving the bed can be uniform. To fulfill this requirement, the jet entering the box is broken and pushed toward the side walls by a baffle plate. The diameter of the baffle plate is $76 \mathrm{~mm}$, being $50 \%$ larger than the jet or pipe diameter, and it is placed at $20 \mathrm{~mm}$, about 1.6 $D_{P}$, from the inlet to the box. After the baffle plate, the flow passes through a net and a honeycomb to reduce its level of fluctuations and also to break down large scale eddies. The net and honeycomb is placed at $50 \mathrm{~mm}\left(4 D_{P}\right)$ and $100 \mathrm{~mm}\left(8 D_{P}\right.$ after the inlet, respectively. The net has square openings with a mesh size of $2 \times 2 \mathrm{~mm}^{2}$ and the cells in the honeycomb have a circular cross section with a diameter of $2 \mathrm{~mm}$. The thickness of the honeycomb in the flow direction is $25 \mathrm{~mm}$.

The inlet to the packed bed is $150 \mathrm{~mm}\left(12 D_{P}\right.$ downstream the honeycomb). At the inlet and outlet of the packed bed square meshes with a mesh size of $4.4 \times 4.4 \mathrm{~mm}^{2}$ and wire diameter of $0.65 \mathrm{~mm}$ are placed. Also to avoid the effect of the sudden contraction at the outlet of the box this contraction is $100 \mathrm{~mm}\left(8 D_{P}\right)$ downstream the bed outlet.

To have optical access to the flow field within the bed, the bed has to transmit light rays without distortion. To have such a medium the refractive index of the working fluid is matched to that of the spheres in the bed. For this purpose, an aqueous solution of ammonium thiocyanat $\left(\mathrm{NH}_{4} \mathrm{SCN}\right)$ is used. This is a transparent liquid and its refractive index can be tuned by variation of the concentration ammonium thiocyanat. This is done with an optical method according to Fig. 2. The main idea is that the light will not refract and instead hit the reference point if the solution and spheres have the same refractive index. So a reference point was defined without any sphere. A sphere was then immersed into the fluid and the indexmatched solution was found by adding water/salt to the initial solution until the light ray hit the reference point regardless of the relative position of the sphere. The concentration, kinematic viscosity and density of the final solution are $60.36 \%, 1.83 \times 10^{-6} \mathrm{~m}^{2} / \mathrm{s}$ and $1127 \mathrm{~kg} / \mathrm{m}^{3}$, 


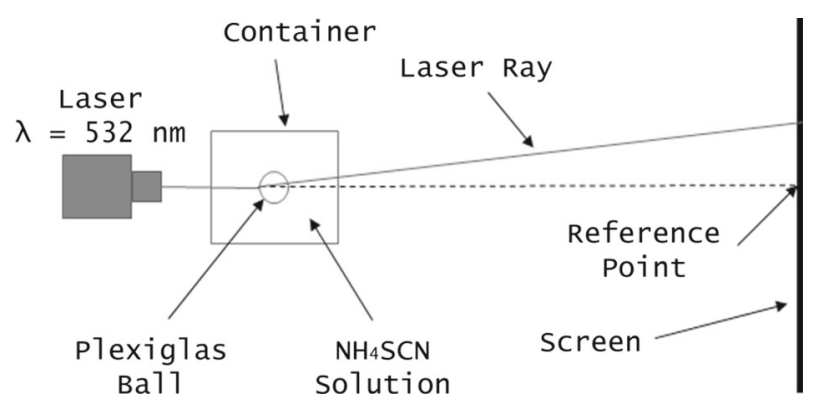

Fig. 2 Schematic of the index matching setup

Table 1 The porosity of each planes

\begin{tabular}{llllll}
\hline Planes & CE00 & CE06 & CE12 & CE18 & CE24 \\
Porosity $(\varphi)$ & 0.233 & 0.476 & 0.381 & 0.381 & 0.393
\end{tabular}

respectively. The viscosity was measured with a calibrated Ostwald viscometer due to the corrosive properties of the fluid.

A commercial PIV system from LaVision $\mathrm{GmbH}$ is used for imaging. This system is based on a double-pulsed Nd:YAG laser at a wavelength of $532 \mathrm{~nm}$ with a maximum frequency of $100 \mathrm{~Hz}$, a minimum inter-frame time for image pairs of $5 \mu \mathrm{s}$, and a LaVision doubleframe FlowMaster Imager Pro camera with spatial resolution of $1280 \times 1024$ pixels per frame with pixel size of $12 \times 12 \mu \mathrm{m}^{2}$. A Nikon AF Nikkor $50 \mathrm{~mm}$ lens was used, with an f-stop of 2.8. The time delay between image pairs was adjusted to restrict seeding particles mean displacements between 6 to 8 pixels. The laser and camera were mounted on a 3D traversing system so that the laser sheet and camera can be moved up to $500 \mathrm{~mm}$ in the $x-, y$ and $z$-directions. Hollow glass spheres with a diameter of $10 \mu \mathrm{m}$ from Dantec were used as seeding particles. The chosen seeding particles are sufficiently small and have a density near to that of index-matched solutions allowing them to closely follow the motion of the fluid (Raffel 2007).

To avoid false vector and facilitate the analysis, the images produced were masked. This was done manually and the interior of spheres cut by the laser sheet, as well as, minor reflections from seeding particles trapped on the surface on the particles were covered. The resulting porosity of each plane is presented in Table 1 with an average $\varphi$ of about 0.37 . This is less than about 0.41 as derived from geometrical calculations. The reason to this is that the porosity is higher at the walls of the cell as compared to the bulk and that the masking covers slightly more than the particles. The PIV software DaVis 7.2.2 based on a cross-correlation algorithm was used to derive velocity vectors. A multi-step correlation processing algorithm with decreasing window size was used to evaluate recorded images with a final window size of $32 \times 32$ pixels. The overlap of windows was constant at $75 \%$ for all steps. This final window size gives a vector spacing of $0.28 \mathrm{~mm}$ or 44 vectors per particle diameter. Vectors, for which, RMS exceeds 1.5 times of the neighboring vectors RMS were recognized as false vectors and were removed. At the end, a $3 \times 3$ Gaussian kernel was used to smooth the vector field. All velocity data presented here are located in the $x-y$ plane near the center of the bed. All presented time-averaged velocity fields at each $R e_{\mathrm{p}}$ were calculated from 712 instantaneous velocity fields recorded with sampling frequency of $75 \mathrm{~Hz}$.

The errors during PIV measurements may be of systematic and random type, see Coleman and Steele (1999). The former includes refraction through the model walls, calibration of 
measurement equipment, and camera viewing angle and may be difficult to detect and are instead reduced by a careful setup, Larsson et al. (2015). Although such a procedure has been applied in the current setup a biased error is assumed to be about $0.5 \%$ following Larsson et al. (2015). The main source of random error is due to the sub-pixel estimation during the cross-correlation. This error has been estimated to be $10 \%$ of the particle image diameter, (Balakumar et al. 2009). Hence the error in the measured velocity vector in each interrogation area is therefore about $1 \%$. The errors approximated are relatively small and will not influence the results to any larger extent and certainly not the main conclusions. It should be mentioned that new and rather complex methods to derive the error in PIV measurements have recently been suggested, i.e., Charonko and Vlachos (2013) and Wieneke (2015) but this has not yet resulted in a standard method.

\section{Theory}

The particle diameter, $D_{p}$ and the averaged interstitial velocity, $U_{\text {int }}$ are chosen to be characteristic length scales for the bed resulting in a $R e_{\mathrm{p}}$ according to Eq. 1 . The interstitial velocity can be calculated from the Darcian velocity, $U_{\text {Darcy }}$, Eq. 2 , while the Darcian velocity can be computed from the volumetric flow rate, $Q$ via Eq. 3 .

$$
\begin{aligned}
R e_{p} & =\frac{U_{\mathrm{int}} D_{p}}{v}, \\
U_{\text {int }} & =\frac{U_{\text {Darcy }}}{\varphi}, \\
U_{\text {Darcy }} & =\frac{Q}{A_{\text {Bed }}} .
\end{aligned}
$$

Here $A_{\text {bed }}$ is the bed cross sectional $0.1 \times 0.1 \mathrm{~m}^{2}$ ) area normal to the flow direction and $\varphi=$ 0.414 . In the measured velocity fields $u, u_{x}$ and $u_{y}$ represent in-plane velocity magnitude, $x$ - and $y$-direction velocity components, respectively. All the velocities are normalized with $U_{\text {int }}$ and denoted by $u^{*}, u_{x}^{*}$ and $u_{y}^{*}$. In addition to velocity plots, the normalized probability distribution function (NPDF) is used to scrutinize time-averaged velocity fields at the different sections of the packed bed for $20 \leq R e_{\mathrm{p}} \leq 3220$. The NPDF of the velocity shows the probability distribution of velocities according to:

$$
F(v)=P(V<v)=\sum_{a \leq v} \int_{-\infty}^{v} p(a) .
$$

normalized with the probability of the most probable velocity. Hence the probability of the most probable velocity of the velocity spectrum is equal to unity.

\section{Results and Discussions}

The overall behavior of the flow is revealed with pressure measurements and global studies of the results from PIV measurements. Then the details of the spatial variations the in flow are scrutinized. Most of the data presented relate to scaled variables and for clarity the velocities $U_{\text {int }}$ and $U_{\text {Darcy }}$ are plotted as a function of $R e_{\mathrm{p}}$ in Fig. 3. 


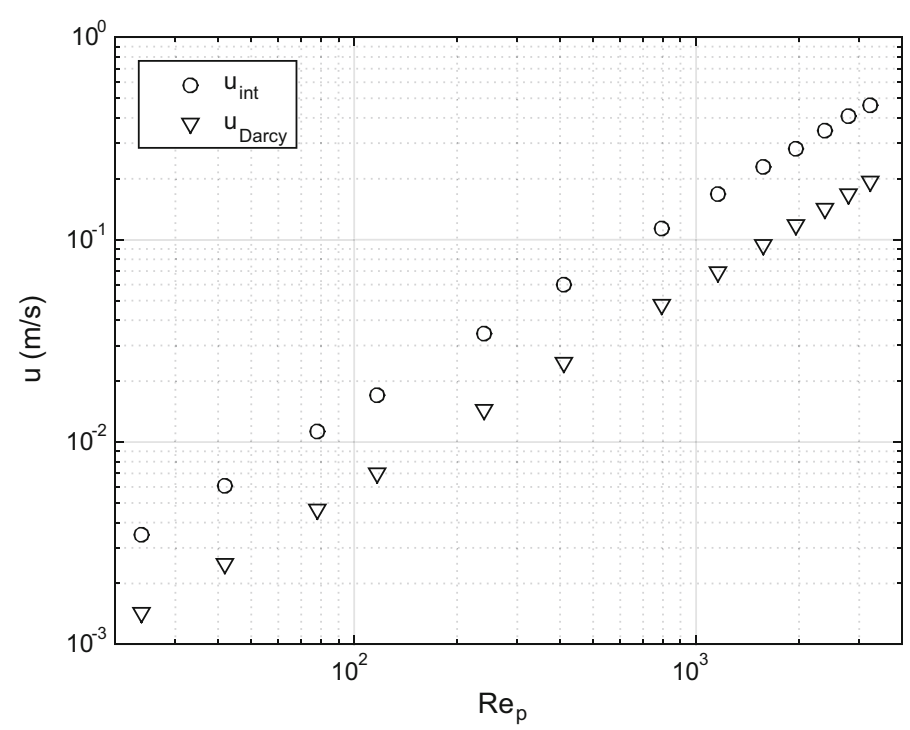

Fig. 3 Velocities as derived from measurements with the flow meter, the geometry of the Plexiglas box and the overall porosity of the bed

\subsection{Overall Behavior of the Flow}

Let us study the detailed in-plane flow in three of the planes, the mid-plane, $6 \mathrm{~mm}$ from the mid-plane and $24 \mathrm{~mm}$ from the mid-plane, see Fig. $4 \mathrm{a}-\mathrm{c}$. The mid-plane represents a rather dense area with a relatively low porosity, while the porosity in the plane $6 \mathrm{~mm}$ from this plane is relatively high, see Table 1 . The plane $24 \mathrm{~mm}$ from the midplane is the plane nearest to the wall in this investigation, $26 \mathrm{~mm}$ from the wall. In the plots, color represents the magnitude of in-plane velocity, $u^{*}$, and the arrows the direction. The presented time-averaged velocity fields at each $R e_{\mathrm{p}}$ were calculated from 712 instantaneous velocity fields with a sampling frequency of $75 \mathrm{~Hz}$. As seen the magnitude of the time-averaged velocity varies considerably as a function of spatial co-ordinate regardless of $R e_{\mathrm{p}}$ and, as seems, the amount of relatively high velocities decreases with $R e_{\mathrm{p}}$. There are also indications of streaks of high velocity within the planes, see, e.g., Fig. 4b lower red areas. The arrows, in their turn, indicate a more disordered flow field as $R e_{\mathrm{p}}$ increases, e.g., middle of Fig. $4 \mathrm{c}$, compare $R e_{\mathrm{p}}=20$ and $R e_{\mathrm{p}}=410$. The distortion predominately takes place in low velocity areas marked with blue arrows.

Pressure drop measurements over the bed show that the flow deviates from being Darcian at about $R e_{\mathrm{p}}>80$, see Fig. 5 where the apparent permeability, $K$, divided with the Darcian flow permeability, $K_{0}$, is plotted as a function of $R e_{\mathrm{p}}$. The result is in accordance with numerical simulations presented in (Hellström et al. 2010). Notice, that the detailed flow can still deviate from the Stokes flow extreme at lower $R e_{\mathrm{p}}$ but this is not reflected in the measurements of the pressure and thus the overall apparent permeability. The decrease in the apparent permeability with $R e_{\mathrm{p}}$ continues which can be interpreted as an increasing amount of inertia dominated flow and even turbulent effects. Notice also the slight increase in permeability at $R e_{\mathrm{p}}>800$. This is surprising and can be a result of unknown errors in the measurements. The detailed theoretical analysis in Adler et al. (2013) indicates, however, a similar behavior of their variable $h$. So this is a topic for future studies and is shortly discussed 

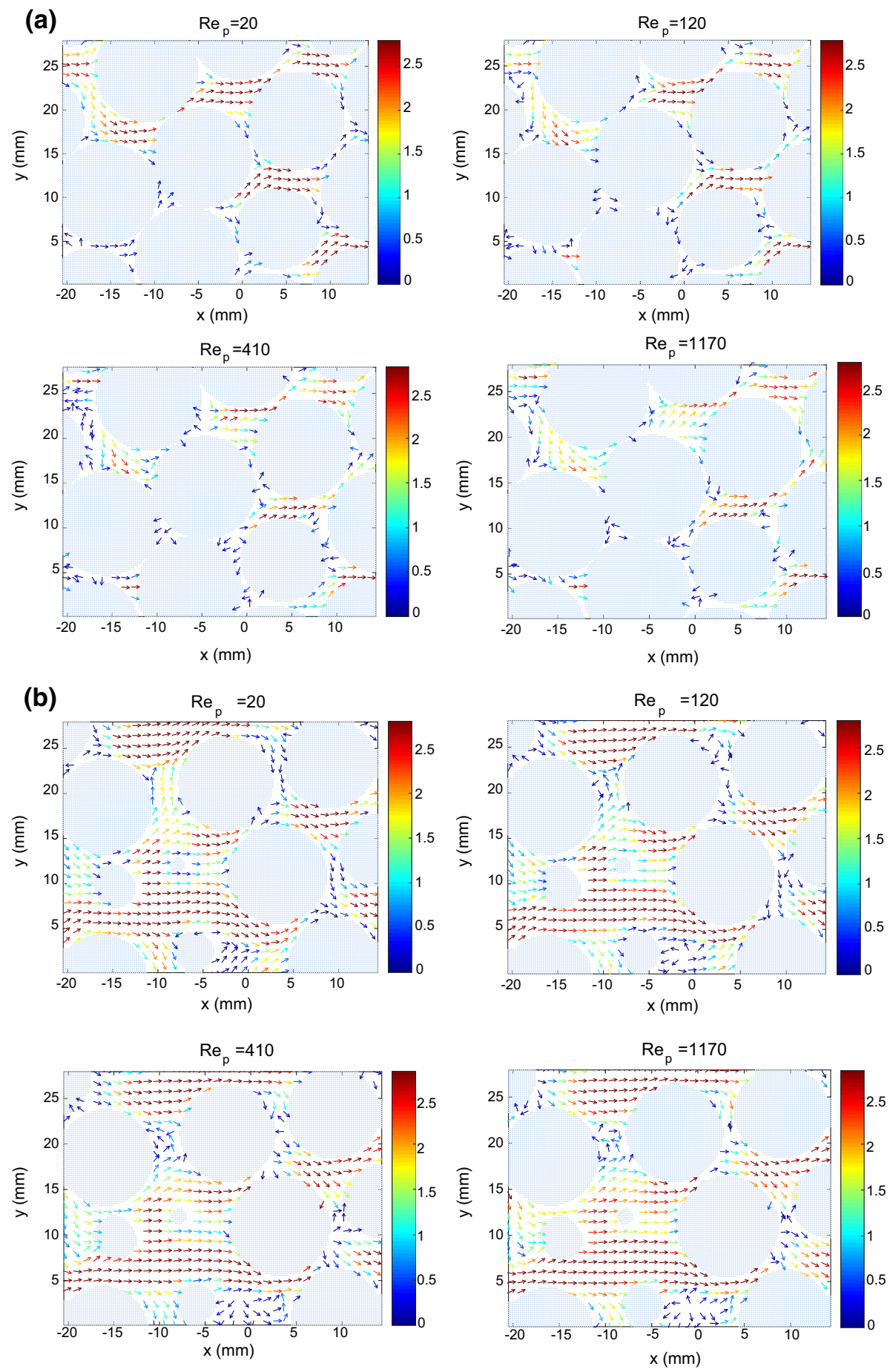

Fig. 4 a-c Time-averaged $u^{*}$ at $R e_{\mathrm{p}}=20,120,410,1170$ for three planes. The main flow is from left to right. a Midplane b $6 \mathrm{~mm}$ from midplane, c $24 \mathrm{~mm}$ from midplane 

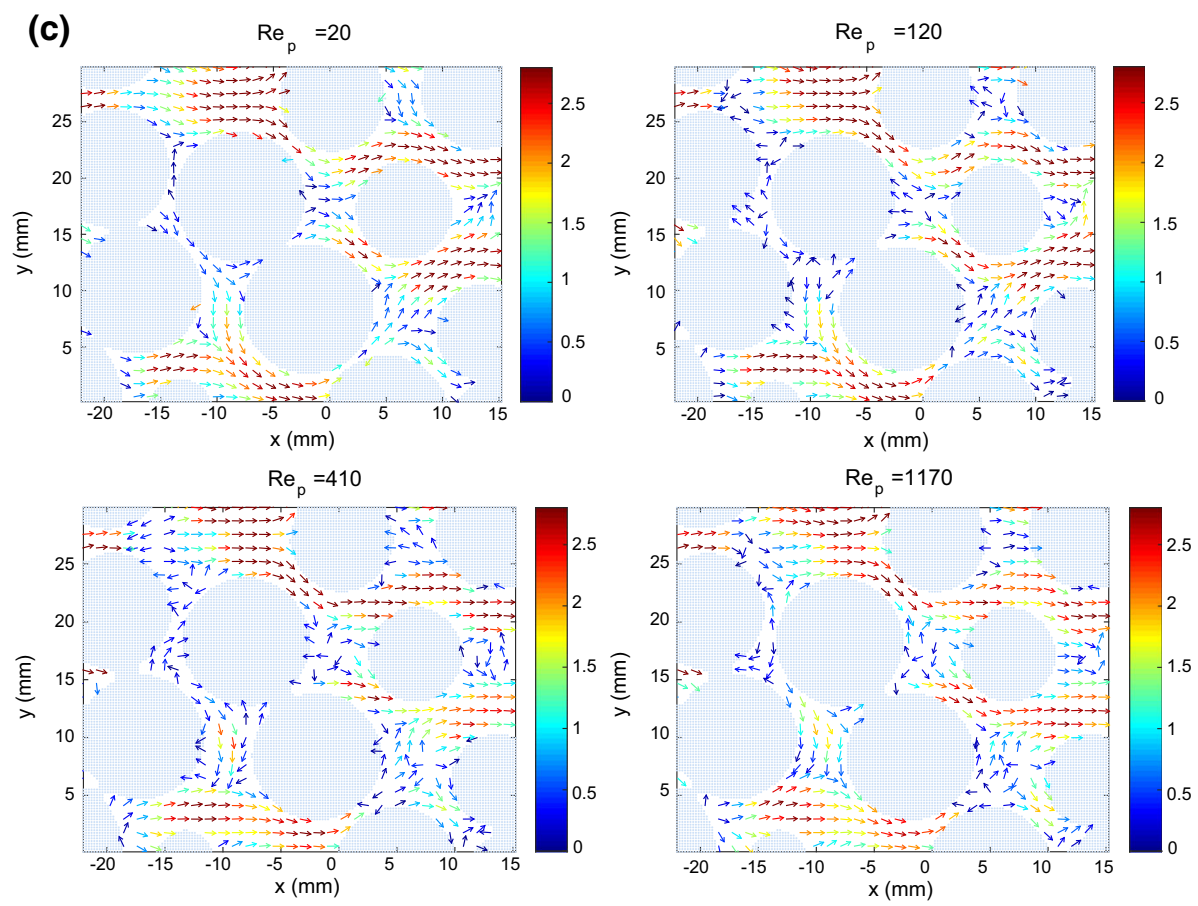

Fig. 4 continued

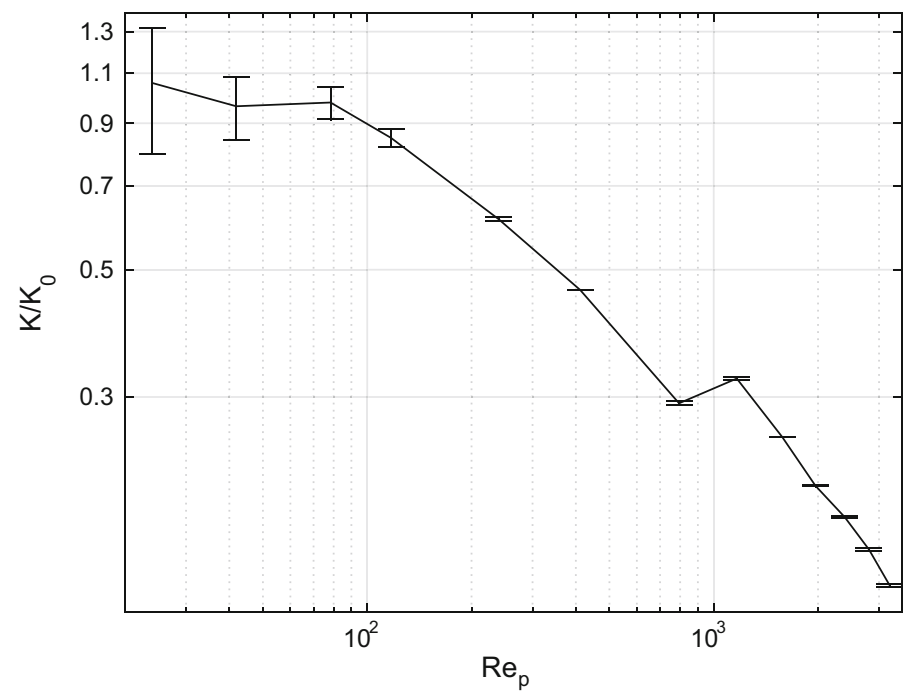

Fig. 5 The normalized apparent permeability of the porous bed. The bars denote error according to derivations

in-connection to Fig. 6. The maximum error bars in Fig. 5 are derived based on the error estimates presented in Table 2. From the values in this table also the maximum deviation in $R e_{\mathrm{p}}$ can be derived to $1.1 \%$. 


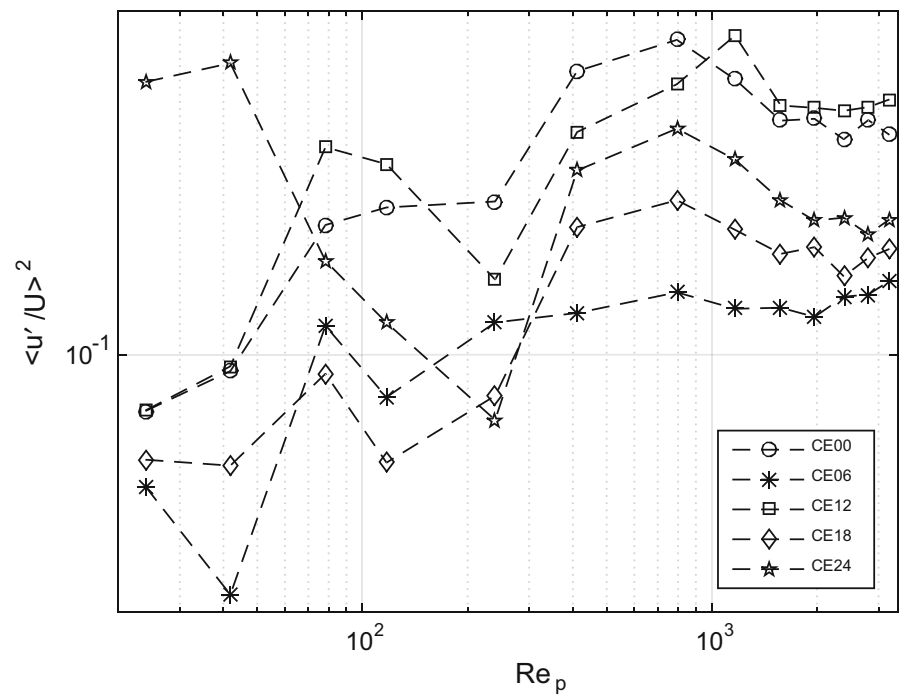

Fig. 6 Area-averaged velocity fluctuations as revealed from PIV

Table 2 Estimates of maximum error

\begin{tabular}{ll}
\hline Parameter & Error \\
\hline Flow rate (Q) & $0.003 \mathrm{Q}$ \\
Area (A) & $1.010^{-6} \mathrm{~m}^{2}$ \\
Porosity & 0.0027 \\
Diameter & $0.05 \mathrm{E}-3 \mathrm{~m}$ \\
Viscosity & $0.006 \mathrm{cSt}$ \\
Density & $3.4 \mathrm{~kg} / \mathrm{m}^{3}$ \\
Length & $0.001 \mathrm{~m}$ \\
Pressure & $2 \mathrm{~Pa}$ \\
\hline
\end{tabular}

The magnitude of the area-averaged time fluctuations of the in-plane velocity also changes with $R e_{\mathrm{p}}$, cf. Fig. 6. The general trend is that the magnitude increases with $R e_{\mathrm{p}}$ and reaches a maximum for $R e_{\mathrm{p}} \approx 800$. The increase is not constant and there are indications of a local maximum also at $R e_{\mathrm{p}} \approx 80$. The rather steep increase in the magnitude of fluctuations in the interval $40<R e_{\mathrm{p}}<80$ may be due to instabilities caused by inertia Hellström et al. (2010). The fluctuations do not, however, influence the pressure measurements to any large extent until $R e_{\mathrm{p}}>80$, Fig. 5. There is an additional increase in the level of fluctuations at $R e_{\mathrm{p}}>250$, which may denote the transition from inertia dominated flow to turbulent flow, see Fig. 5. This is in agreement with numerical results obtained in (Hellström et al. 2010). For $R e_{\mathrm{p}}>1500$, the level of velocity fluctuations becomes independent of $R e_{\mathrm{p}}$, which is an indication of turbulent flow. The increase in apparent permeability at $R e_{\mathrm{p}} \approx 800$, as shown in Fig. 5, may therefore be due to removal of inertia dominated large amplitude fluctuations, see Fig. 6. Notice that although the trends mentioned above are obvious, the level of fluctuations differ between the planes. This is likely due to geometrical differences. To exemplify, in the plane with the highest porosity the 
Table 3 Approximate flow regimes within the porous bed

\begin{tabular}{ll}
\hline$R e_{\mathrm{p}}$ & Flow regime \\
\hline$R e_{\mathrm{p}}<40$ & Stokes flow dominates \\
$40<R e_{\mathrm{p}}<250$ & Stokes-to-inertia transition \\
$250<R e_{\mathrm{p}}<1500$ & Inertia to turbulent transition \\
$1500<R e_{\mathrm{p}}$ & Turbulent flow
\end{tabular}
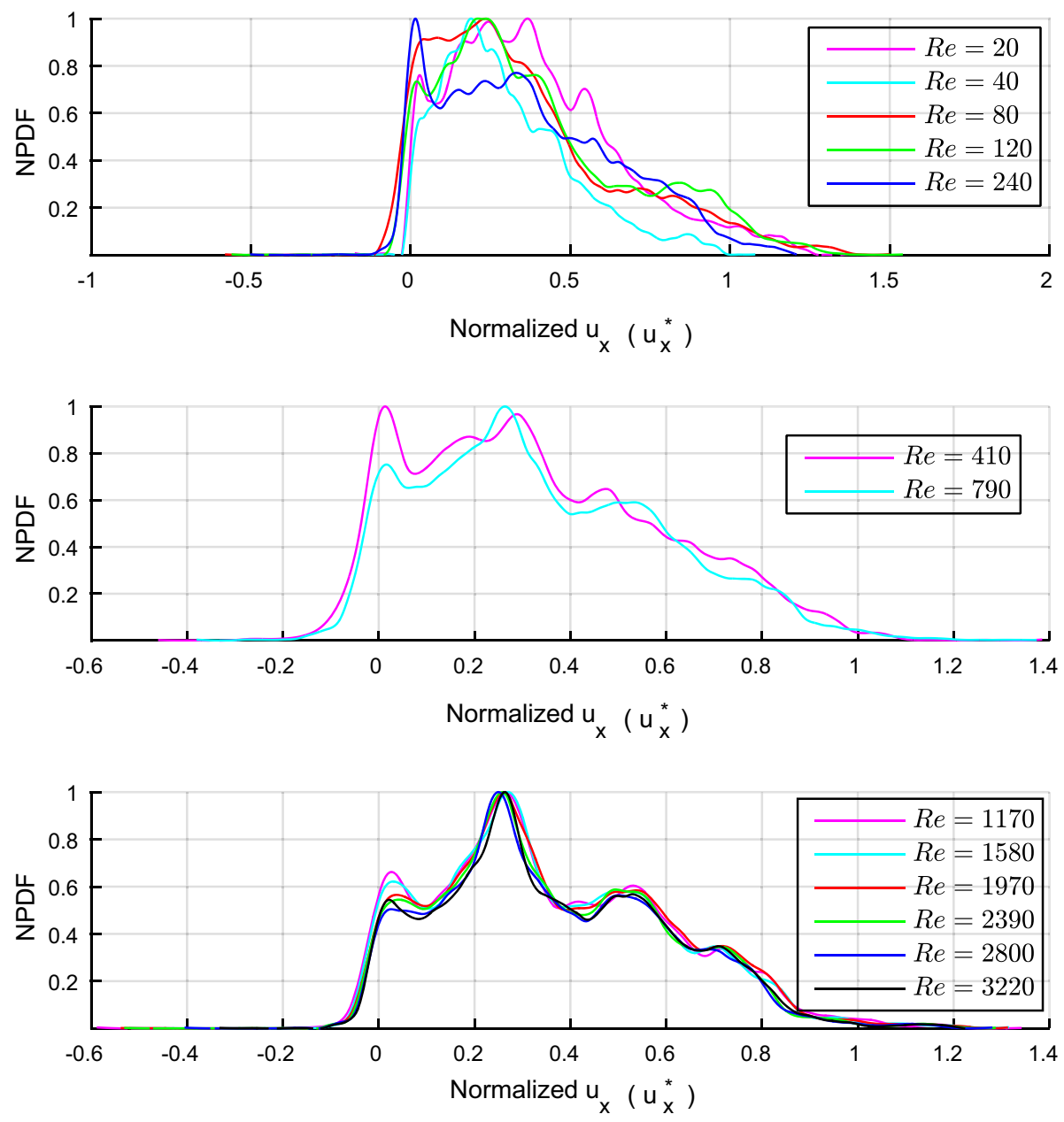

Fig. 7 Normalized PDF of $u_{x}^{*}$ for $R e_{\mathrm{p}}$ as indicated

velocity fluctuation is low and in the plane with the lowest porosity the velocity fluctuation is high, see Fig. 6. Based on Figs. 5 and 6, four flow regimes can be defined according to Table 3. 


\subsection{Detailed Studies of the Flow}

In this section, the statistical characteristics of $u_{x}^{*}, u_{y}^{*}$ and $u^{*}$ are presented for all planes at different $R e_{\mathrm{p}}$ by usage of the NPDF of the velocity field as defined in Chapter 3 . Three regions of $R e_{\mathrm{p}}$ are studies separately, $20 \leq R e_{\mathrm{p}} \leq 240,410 \leq R e_{\mathrm{p}} \leq 790$ and $1170 \leq R e_{\mathrm{p}} \leq 3220$. The reason for this division is the characteristics of the studied statistical parameter as well as possible flow regimes according to Table 3 . The most significant result of this investigation is that $u_{x}^{*}$ is self-similar for the highest range of $R e_{\mathrm{p}}$ studied, turbulent flow, see Fig. 7 that includes the velocity distribution in all five planes. This strongly supports results in Patil and Liburdy 2013 who studied smaller areas than done in the current paper but also obtained self-similarity for high $R e_{\mathrm{p}}$.

Figure 7 also indicates self-similarity for the lowest range of $R e_{\mathrm{p}}$ with a relatively flat plateau of the most probable $u_{x}^{*}$ for $u_{x}^{*}<0.4$ and then the probability of the velocity spectrum drops rather abruptly which was also observed by Maier et al. (1998) and Moroni et al. (2001). Johns et al. (2000) who studied porous media with MRI obtained a peak for the most probable $u_{x}^{*}$ at Re of about 1 . However for higher $R e$, e.g., $R e=4$, their plots show a small plateau. This is also the case for results in Kutsovsky et al. (1996) obtained with NMR. Here Re up to about 50 is studied and it is clear that the distribution profiles of $u_{x}$ ( $v_{z}$ in their paper) attain a more plateau like shape as Re increases in accordance with our results. For the highest range, in Fig. 7, there are a couple of maximum with the most probable velocity at $u_{x}^{*}$ about 0.4 . When each of the five planes is studied individually it is found that the curves are self-similar but that the maximum appears at different $u_{x}^{*}$. Hence, an even more extensive study may change the position of this maximum for a randomly packed bed of mono-sized spheres. The graphs in Fig. 7 also shows that there are negative $u_{x}^{*}$ for all $R e_{\mathrm{p}}$. A number of studies have reported the presence of recirculation zones as well, i.e., Moroni et al. (2001), Maier et al. (1998), Saeger et al. (1991, 1995), Lebon et al. (1996), Hill et al. (2001). The percentage negative $u_{x}^{*}$, which is an indication of recirculation zones, vary with $R e_{\mathrm{p}}$ according to Fig. 8 where results from each plane are plotted individually. The clear and general trend is that the

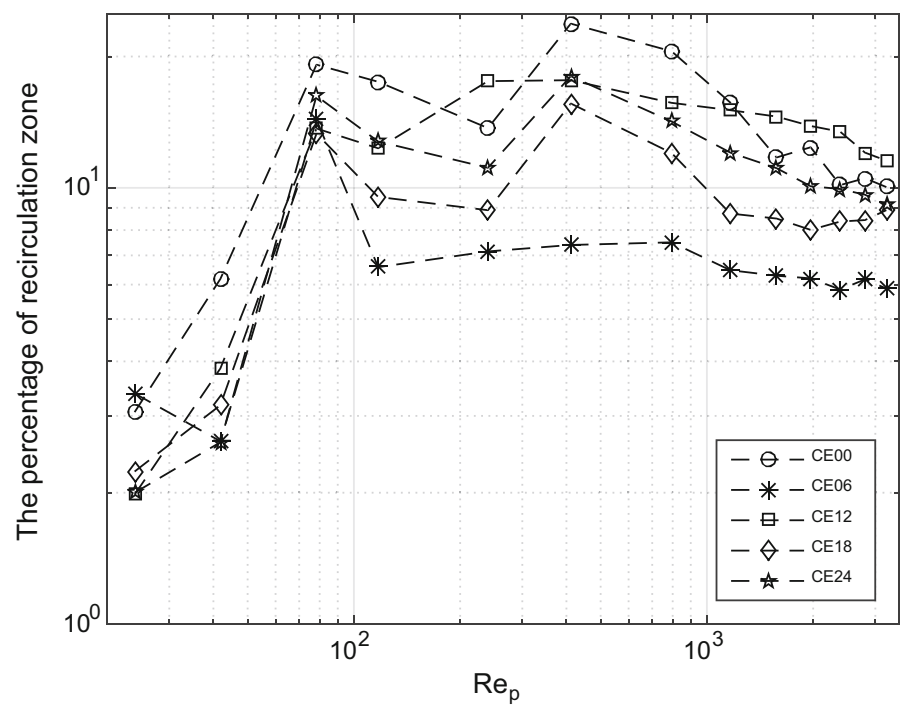

Fig. 8 Percentage recirculation zones for each plane as a function of $R e_{\mathrm{p}}$. 

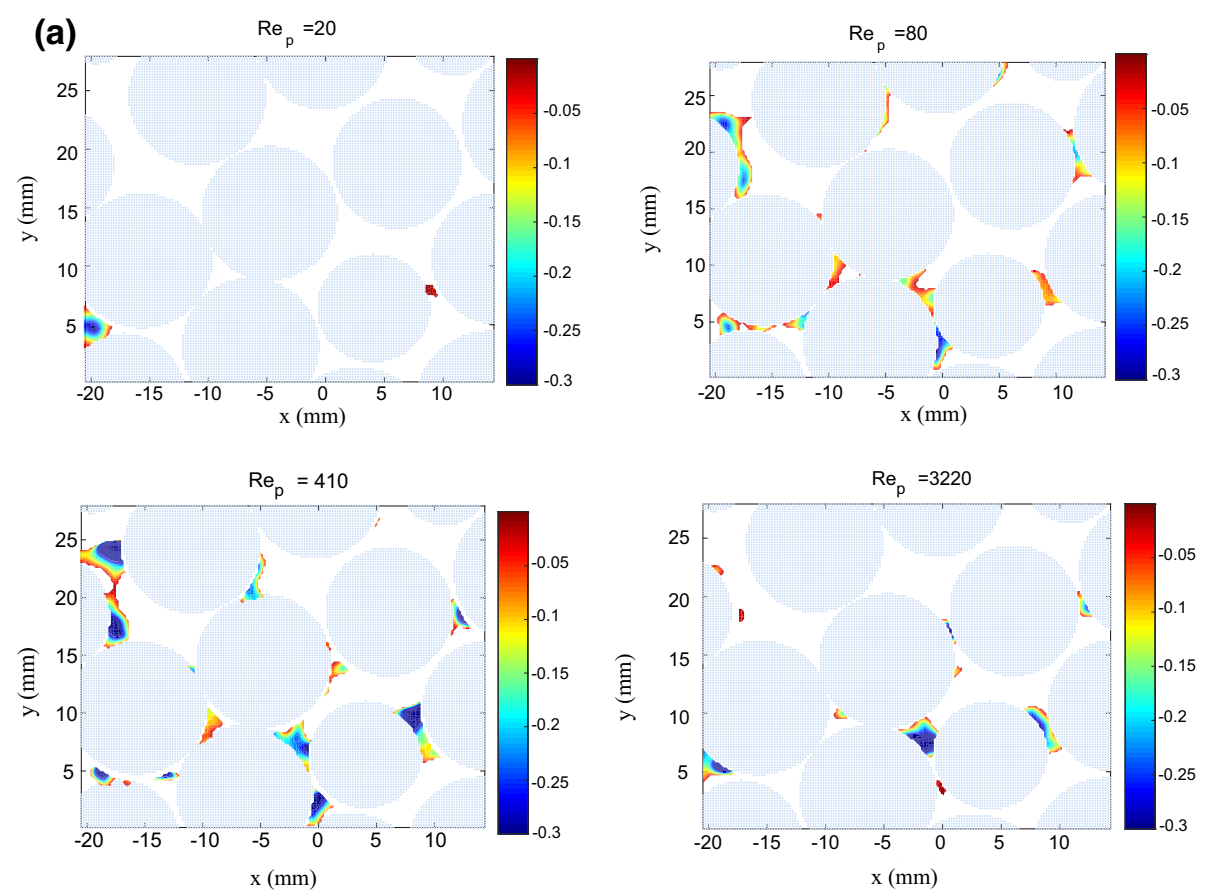

(b)
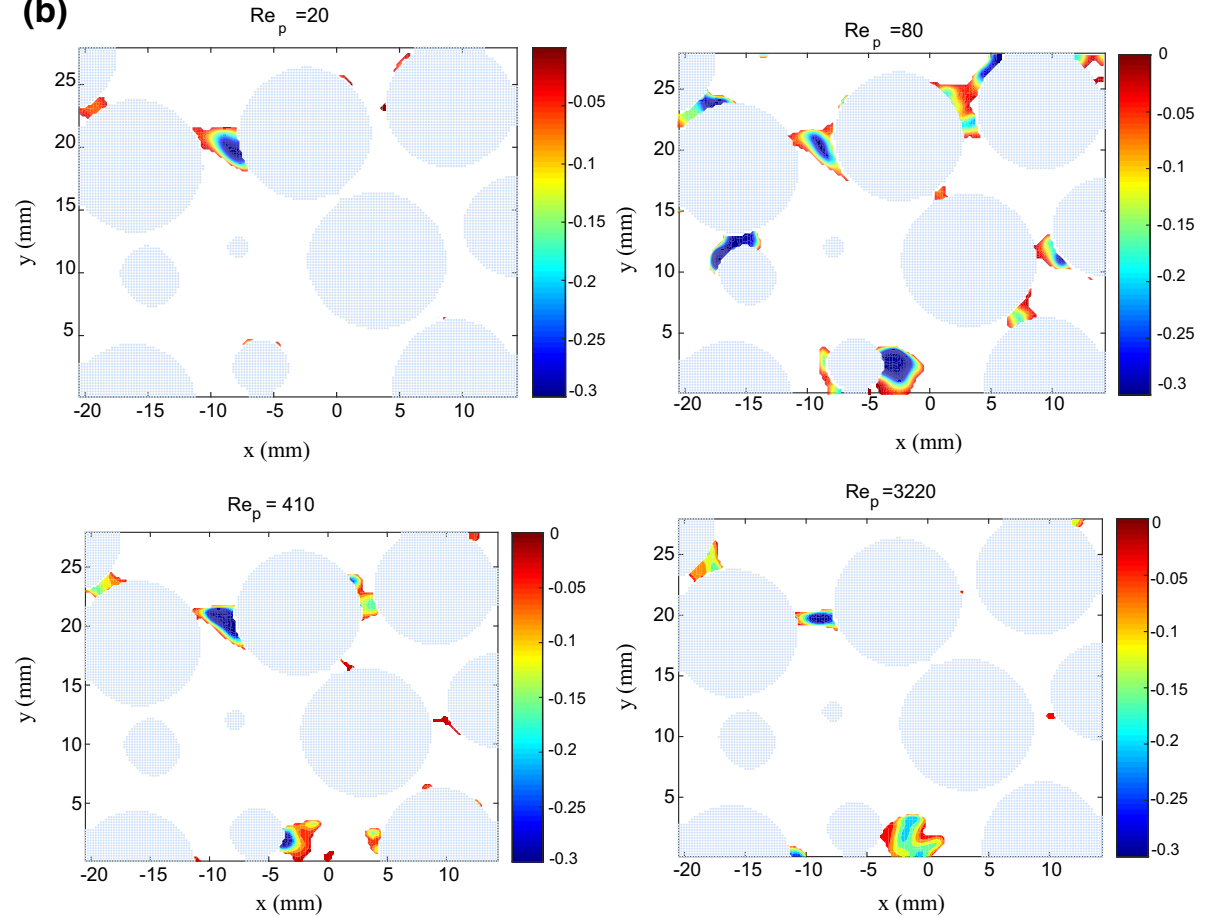

Fig. 9 Backflow of $u_{x}^{*}$ for four $R e_{\mathrm{p}}$ and at three cross sections. a midplane, $\mathbf{b} 6 \mathrm{~mm}$ from midplane, $\mathbf{c} 24 \mathrm{~mm}$ from midplane 

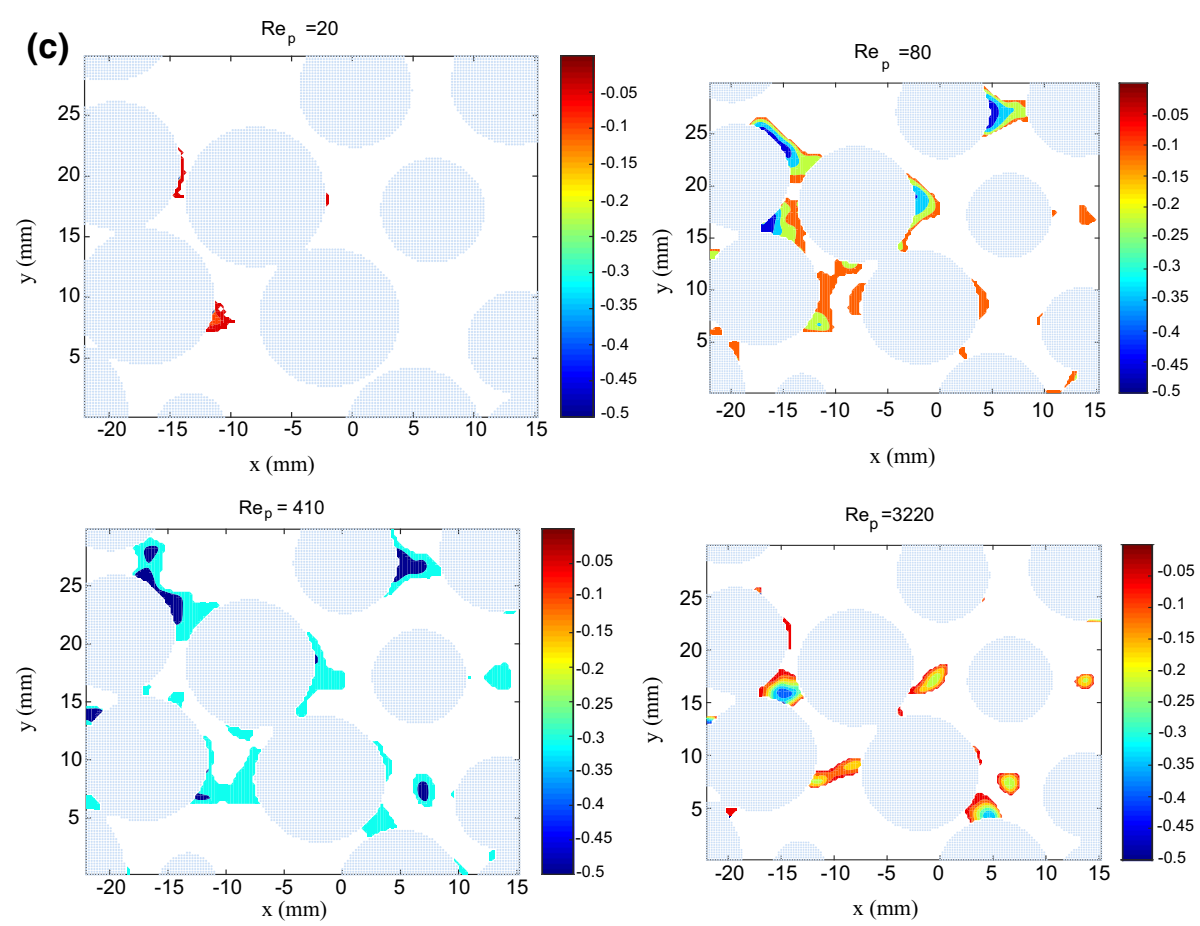

Fig. 9 continued

percentage of the negative axial velocity first increases with $R e_{\mathrm{p}}$ then the amount decreases with $R e_{\mathrm{p}}$ as the flow becomes turbulent. There is less recirculation within the plane $6 \mathrm{~mm}$ from the midplane than within the other planes probably because the overall porosity is about $20 \%$ higher than for the other planes. In Fig. 9a-c the actual position and magnitude of the back-flow is presented for three of the planes at four $R e_{\mathrm{p}}$. The result in Fig. 8 is here visualized and it is clear that the back-flow regions mostly appear in throats between spheres and behind spheres.

The probability distribution of $u_{y}^{*}$ for all planes has a tendency to be symmetric around zero for the lowest range of $R e_{\mathrm{p}}$, see Fig. 10. Also Moroni et al. (2001), Johns et al. (2000); Lebon et al. (1996) reported a symmetric distribution for $u_{y}$ for low $R e_{\mathrm{p}}$. As $\operatorname{Re}_{\mathrm{p}}$ increases the maximum changes slightly toward the negative side and the curves becomes basically the same, self-similar, for $1170 \leq R e_{\mathrm{p}} \leq 3230$. The small but nonzero most probable $u_{y} *$ and the skewness are likely to be an effect of the limited area for the measurements. The distribution of the in-plane absolute velocity, $u^{*}$, first increases and then decreases in width with $R e_{\mathrm{p}}$, see Fig. 11. This is in agreement with the observations in Fig. 4a-c and confirms that the portion relatively high and relatively low velocities decrease as the flow becomes turbulent.

\section{Conclusion}

PIV measurements have been conducted for $20 \leq R e_{\mathrm{p}} \leq 3220$ within a refractive indexmatched packed bed of mono-sized spheres. The measurements were taken for transitional 

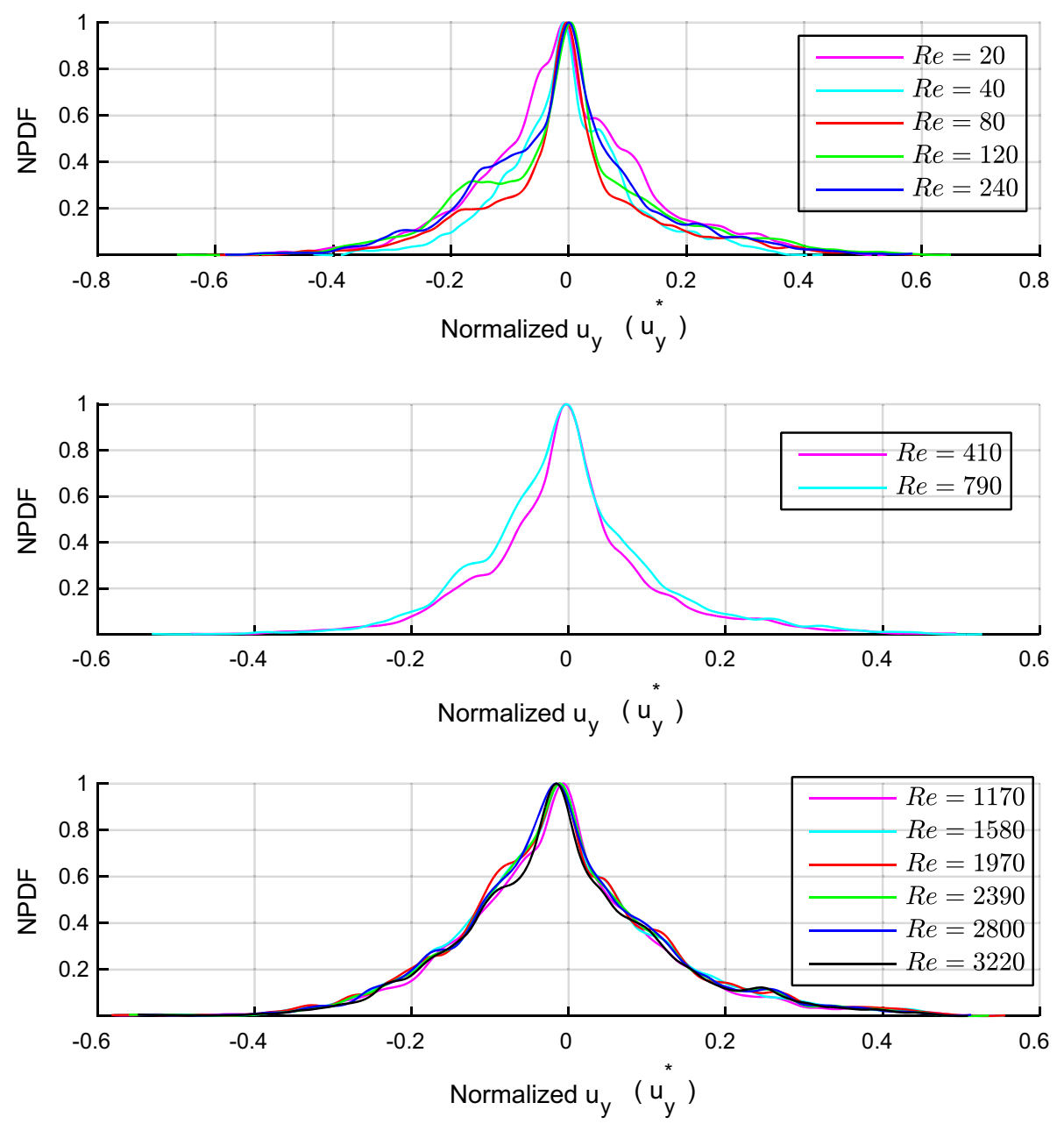

Fig. 10 Normalized PDF of $u_{y}^{*}$ for $R e_{\mathrm{p}}$ as indicated

and turbulent flow and with a relatively large porous bed as to number of spheres and the size of the spheres. In addition, pressure drop measurements along the bed have been taken. The pressure drop measurements suggest that the flow is Darcian until $R e_{\mathrm{p}} \approx 80$ while PIV measurements yield that there are major velocity fluctuations already at $R e_{\mathrm{p}} \approx 80$. Hence fluctuations and inertia effect that appear at this $R e_{\mathrm{p}}$ do not result in any major pressure losses. Focusing on the time-averaged spatial velocity variations it can be concluded that the flow in the bed is self-similar for turbulent flow. There is also an indication that the flow also is self-similar for laminar flow. The time-averaged flow in the bed becomes more uniform as $R e_{\mathrm{p}}$ increases since the amount of relatively high and low velocities decrease with $R e_{\mathrm{p}}$. Recirculation zones appear in the wake of the particles and they increase in strength with $R e_{\mathrm{p}}$ for $R e_{\mathrm{p}}$ up to about 400 . For $R e_{\mathrm{p}}>400$ the share of recirculation zones in the flow 

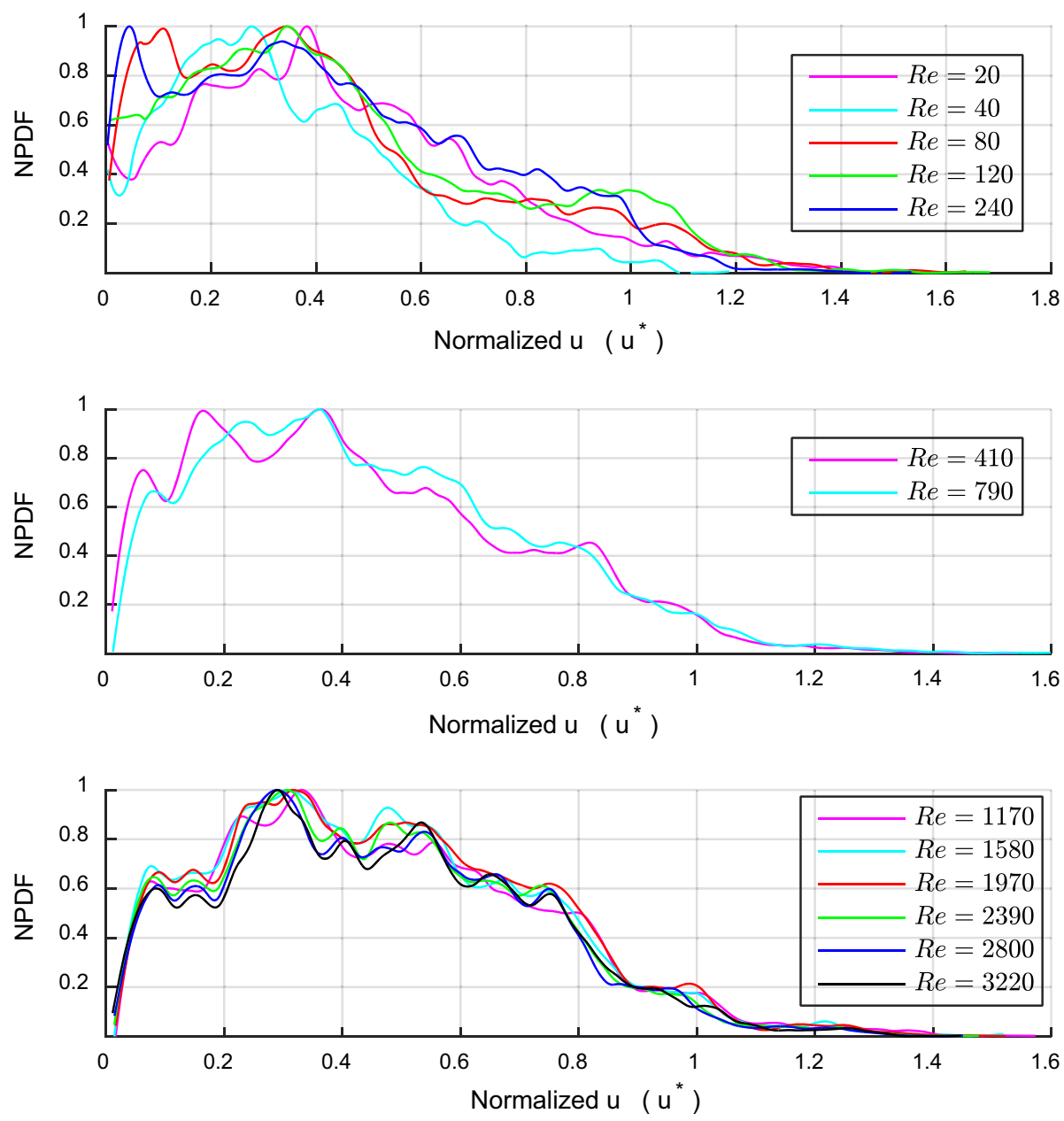

Fig. 11 Normalized PDF of $u^{*}$ for $R e_{\mathrm{p}}$ as indicated

decreases. This is probably due to turbulence. In future work, the temporal variations in the flow will be investigated in detail as well as the effect from spatial and temporal variations on dispersion.

Acknowledgements The work was partly sponsored by the Hjalmar Lundbohm Research Center and the Swedish Research Council (VR) project grant nr 2012-3130.

Open Access This article is distributed under the terms of the Creative Commons Attribution 4.0 International License (http://creativecommons.org/licenses/by/4.0/), which permits unrestricted use, distribution, and reproduction in any medium, provided you give appropriate credit to the original author(s) and the source, provide a link to the Creative Commons license, and indicate if changes were made. 


\section{References}

Adler, P.M., Malevich, A.E., Mityushev, V.V.: Nonlinear correction to Darcy's law for channels with wavy walls. Acta Mech. 224, 1823-1848 (2013)

Adrian, R.J.: Scattering particle characteristics and their effect on pulsed laser measurements of fluid flow: speckle velocimetry versus particle image velocimetry. Appl. Opt. 23(11), 1690-1691 (1984)

Adrian, R.J.: Particle-imaging techniques for experimental fluid mechanics. Ann. Rev. Fluid Mech. 23(1), 261-304 (1991)

Aitomäki, Y., Moreno-Rodriguez, S., Lundström, T.S., Oksman, K.: Vacuum infusion of cellulose nanofibre network composites: influence of porosity. Mater. Des. 95, 204-211 (2016)

Andersson, H., Lundström, T.S., Langhans, N.: Computational fluid dynamics applied to the vacuum infusion process. Polym. Compos. 26(2), 231-239 (2005)

Andrigo, P., Bagatin, R., Pagani, G.: Fixed bed reactors. Catal. Today 52(2), 197-221 (1999)

Antohe, B., Lage, J.: A general two-equation macroscopic turbulence model for incompressible flow in porous media. Int. J. Heat Mass Transf. 40(13), 3013-3024 (1997)

Baldwin, C.A., Sederman, A.J., Mantle, M.D., Alexander, P., Gladden, L.F.: Determination and characterization of the structure of a pore space from 3D volume images. J. Colloid Interface Sci. 181(1), 79-92 (1996)

Balakumar, B.J., Prestridge, K.P., Orlicz, G., Balasubramanian, S., Tomkins, C., Elert, M., Furnish, M.D., Anderson, W.W., Proud, W.G., Butler, W.T.: High resolution experimental measurements of richtmyermeshkov turbulence in fluid layers after reshock using simultaneous PIV-PLIF. In: AIP Conference Proceedings, vol. 11, pp. 659 (2009)

Bear, J.: Dynamics of fluids in porous media. Dover Publication, Reprint of the American Elsevier Publishing Company, Inc., New York (1972)

Burström, P.E.C., Frishfelds, V., Ljung, A.-L., Lundström, T.S., Marjavaara, B.D.: Discrete and continous modelling of convective heat transport in a thin porous layer of mono sized spheres. Heat Mass Transf. (2016). doi:10.1007/s00231-016-1792-7

Chang, C., Watson, A.T.: NMR imaging of flow velocity in porous media. AIChE J. 45(3), 437-444 (1999)

Charonko, J.J., Vlachos, P.P.: Estimation of uncertainty bounds for individual particle image velocimetry measurements from cross-correlation peak ratio. Meas. Sci. Technol. 24, 065301-065316 (2013)

Chu, C., Ng, K.: Flow in packed tubes with a small tube to particle diameter ratio. AIChE J. 35(1), 148-158 (1989)

Coleman, H., Steele, W.: Experimentation and Uncertainty Analysis for Engineers, 2nd edn. Wiley, New York (1999)

Das, S.K.: Jai Ganesh, S., Lundström, T. S.: Modeling of a groundwater mound in a two-dimensional heterogeneous unconfined aquifer in response to precipitation recharge. J. Hydrol. Eng. 20(7), 04014081 (2015)

de Lemos, M.J., Pedras, M.H.: Recent mathematical models for turbulent flow in saturated rigid porous media. J. Fluids Eng. 123(4), 935-940 (2001)

Dixon, A., Cresswell, D.: Effective heat transfer parameters for transient packed-bed models. AIChE J. 32(5), 809-819 (1986)

Eigenberger, G., Ruppel, W.: Catalytic Fixed-Bed Reactors. Wiley, Hoboken (1992)

Ergun, S.: Fluid flow through packed columns. Chem. Eng. Progr. 48(2), 89-94 (1952)

Fabricius, J., Hellström, J.G.H., Lundström, T.S., Miroshnikova, E., Wall, P.: Darcy's law for flow in thin periodic porous media. Transp. Porous Media (2016). doi:10.1007/s11242-016-0702-2

Geller, J.T., Hunt, J.R.: Mass transfer from nonaqueous phase organic liquids in water-saturated porous media. Water Res. Res. 29(4), 833-845 (1993)

Getachew, D., Minkowycz, W., Lage, J.: A modified form of the $\kappa-\varepsilon$ model for turbulent flows of an incompressible fluid in porous media. Int. J. Heat Mass Transf. 43(16), 2909-2915 (2000)

Gladden, L., Akpa, B., Anadon, L., Heras, J., Holland, D., Mantle, M., et al.: Dynamic MR imaging of single-and two-phase flows. Chem. Eng. Res. Des. 84(4), 272-281 (2006)

Gunn, D.: Axial and radial dispersion in fixed beds. Chem. Eng. Sci. 42(2), 363-373 (1987)

Hellström, J.G.I., Jonsson, P.J.P., Lundström, T.S.: Laminar and turbulent flowthrough an array of cylinders. J. Porous Media 13(12), 1073-1085 (2010)

Hill, R.J., Koch, D.L., Ladd, A.J.: The first effects of fluid inertia on flows in ordered and random arrays of spheres. J. Fluid Mech. 448, 213-241 (2001a)

Hill, R.J., Koch, D.L., Ladd, A.J.: Moderate-Reynolds-number flows in ordered and random arrays of spheres. J. Fluid Mech. 448, 243-278 (2001b)

Hlushkou, D., Tallarek, U.: Transition from creeping via viscous-inertial to turbulent flow in fixed beds. J. Chromatogr. 1126(1-2), 70-85 (2006) 
Huang, A.Y., Huang, M.Y., Capart, H., Chen, R.: Optical measurements of pore geometry and fluid velocity in a bed of irregularly packed spheres. Exp. Fluids 45(2), 309-321 (2008)

Imhoff, P.T., Jaffé, P.R., Pinder, G.F.: An experimental study of complete dissolution of a nonaqueous phase liquid in saturated porous media. Water Res. Res. 30(2), 307-320 (1994)

Imhoff, P.T., Thyrum, G.P., Miller, C.T.: Dissolution fingering during the solubilization of nonaqueous phase liquids in saturated porous media: 2. Experimental observations. Water Res. Res. 32(7), 1929-1942 (1996)

Johns, M., Gladden, L.: Magnetic resonance imaging study of the dissolution kinetics of octanol in porous media. J. Colloid Interface Sci. 210(2), 261-270 (1999)

Johns, M., Sederman, A., Bramley, A., Gladden, L., Alexander, P.: Local transitions in flow phenomena through packed beds identified by MRI. AIChE J. 46(11), 2151 (2000)

Johnston, W., Dybbs, A., Edwards, R.: Measurement of fluid velocity inside porous media with a laser anemometer. Phys. Fluids (1958-1988) 18(7), 913-914 (1975)

Jourak, A., Frishfelds, V., Hellström, J.G.I., Lundström, T.S., Herrmann, I., Hedström, A.: Longitudinal dispersion coefficient: effects of particle-size distribution. Transp. Porous Media 99(1), 1-16 (2013)

Jourak, A., Hellström, J.G.I., Lundström, T.S., Frishfelds, V.: Numerical derivation of dispersion coefficients for flow through three-dimensional randomly packed beds of monodisperse spheres. AIChE J. 60(2), 749-761 (2014)

Khalili, A., Basu, A., Pietrzyk, U.: Flow visualization in porous media via positron emission tomography. Phys. Fluids (1994-Present) 10(4), 1031-1033 (1998)

Khayamyan, S., Lundström, T.: Interaction between the flow in two nearby pores within a porous material during transitional and turbulent flow. J. Appl. Fluid Mech. 8(2), 281-290 (2015)

Khayamyan, S., Lundström, T.S., Gustavsson, L.H.: Experimental investigation of transitional flow in porous media with usage of a pore doublet model. Transp. Porous Media 101(2), 333-348 (2014)

Kutsovsky, Y., Scriven, L., Davis, H., Hammer, B.: NMR imaging of velocity profiles and velocity distributions in bead packs. Phys. Fluids (1994-Present) 8(4), 863-871 (1996)

Kuwahara, F., Kameyama, Y., Yamashita, S., Nakayama, A.: Numerical modeling of turbulent flow in porous media using a spatially periodic array. J. Porous Media 1(1), 47-55 (1998)

Lachhab, A., Zhang, Y., Muste, M.V.: Particle tracking experiments in match-index-refraction porous media. Groundwater 46(6), 865-872 (2008)

Larsson, I.A.S., Johansson, S., Lundström, T.S., Marjavaara, B.D.: PIV/PLIF experiments of jet mixing in a model of a rotary kiln. Exp Fluids 56, 111 (2015). doi:10.1007/s00348-015-1984-9

Lebon, L., Oger, L., Leblond, J., Hulin, J., Martys, N., Schwartz, L.: Pulsed gradient NMR measurements and numerical simulation of flow velocity distribution in sphere packings. Phys. Fluids (1994-Present) 8(2), 293-301 (1996)

Lee, K., Howell, J.: Forced convective and radiative transfer within a highly porous layer exposed to a turbulent external flow field. In: Proceedings of the 1987 ASME-JSME Thermal Engineering Joint Conference, vol. 2, pp. 377-386 (1987)

Ljung, A., Frishfelds, V., Lundström, T.S., Marjavaara, B.D.: Discrete and continuous modeling of heat and mass transport in drying of a bed of iron ore pellets. Dry. Technol. 30(7), 760-773 (2012)

Ljung, A., Staffan Lundström, T., Daniel Marjavaara, B., Tano, K.: Convective drying of an individual iron ore pellet-analysis with CFD. Int. J. Heat Mass Transf. 54(17), 3882-3890 (2011)

Maier, R.S., Kroll, D., Kutsovsky, Y., Davis, H., Bernard, R.S.: Simulation of flow through bead packs using the lattice Boltzmann method. Phys. Fluids (1994-Present) 10(1), 60-74 (1998)

Masuoka, T., Takatsu, Y.: Turbulence model for flow through porous media. Int. J. Heat Mass Transf. 39(13), 2803-2809 (1996)

Moroni, M., Cushman, J.H.: Statistical mechanics with three-dimensional particle tracking velocimetry experiments in the study of anomalous dispersion. II. Experiments. Phys. Fluids (1994-Present) 13(1), 81-91 (2001)

Nakayama, A., Kuwahara, F.: A macroscopic turbulence model for flow in a porous medium. J. Fluids Eng. 121(2), 427-433 (1999)

Northrup, M.A., Kulp, T.J., Angel, S.M., Pinder, G.F.: Direct measurement of interstitial velocity field variations in a porous medium using fluorescent-particle image velocimetry. Chem. Eng Sci. 48(1), 13-21 (1993)

Odenberger, P.T., Andersson, H., Lundström, T.: Experimental flow-front visualisation in compression moulding of SMC. Compos. Part A Appl. Sci. Manuf. 35(10), 1125-1134 (2004)

Ogawa, K., Matsuka, T., Hirai, S., Okazaki, K.: Three-dimensional velocity measurement of complex interstitial flows through water-saturated porous media by the tagging method in the MRI technique. Meas. Sci. Technol. 12(2), 172 (2001) 
Patil, V.A., Liburdy, J.A.: Flow characterization using PIV measurements in a low aspect ratio randomly packed porous bed. Exp. Fluids 54(4), 1-19 (2013a)

Patil, V.A., Liburdy, J.A.: Turbulent flow characteristics in a randomly packed porous bed based on particle image velocimetry measurements. Phys. Fluids 25, 043304 (2013b)

Payatakes, A.: Dynamics of oil ganglia during immiscible displacement in water-wet porous media. Ann. Rev. Fluid Mech. 14(1), 365-393 (1982)

Pedras, M.H., de Lemos, M.J.: On the definition of turbulent kinetic energy for flow in porous media. Int. Commun. Heat Mass Transf. 27(2), 211-220 (2000)

Pedras, M.H., de Lemos, M.J.: Macroscopic turbulence modeling for incompressible flow through undeformable porous media. Int. J. Heat Mass Transf. 44(6), 1081-1093 (2001)

Pettersson, P., Lundström, T.S., Wassvik, E.: Modeling pressure distribution in a belt press during manufacture of fiberboards. Wood Fiber Sci. 39(3), 493-501 (2007)

Peurrung, L.M., Rashidi, M., Kulp, T.J.: Measurement of porous medium velocity fields and their volumetric averaging characteristics using particle tracking velocimetry. Chem. Eng. Sci. 50(14), 2243-2253 (1995)

Powers, S.E., Abriola, L.M., Weber, W.J.: An experimental investigation of nonaqueous phase liquid dissolution in saturated subsurface systems: transient mass transfer rates. Water Res. Res. 30(2), 321-332 (1994)

Raffel, M., Willert, C.E., Kompenhans, J.: Particle image velocimetry: a practical guide, 2nd edn. Springer, Berlin (2007)

Saeger, R., Scriven, L., Davis, H.: Flow, conduction, and a characteristic length in periodic bicontinuous porous media. Phys. Rev. A 44(8), 5087 (1991)

Saeger, R., Scriven, L., Davis, H.: Transport processes in periodic porous media. J. Fluid Mech. 299, 1-15 (1995)

Saleh, S., Thovert, J., Adler, P.: Measurement of two-dimensional velocity fields in porous media by particle image displacement velocimetry. Exp. Fluids 12(3), 210-212 (1992)

Sederman, A., Johns, M., Alexander, P., Gladden, L.: Structure-flow correlations in packed beds. Chem. Eng. Sci. 53(12), 2117-2128 (1998)

Stephenson, J., Stewart, W.: Optical measurements of porosity and fluid motion in packed beds. Chem. Eng. Sci. 41(8), 2161-2170 (1986)

Suekane, T., Yokouchi, Y., Hirai, S.: Inertial flow structures in a simple-packed bed of spheres. AIChE J. 49(1), 10-17 (2003)

Wang, H., Takle, E.S.: Boundary-layer flow and turbulence near porous obstacles. Bound. Layer Meteorol. 74(1-2), 73-88 (1995)

Westerweel, J.: Fundamentals of digital particle image velocimetry. Meas. Sci. Technol. 8(12), 1379 (1997)

Wieneke, B.: PIV uncertainty quantification from correlation statistics. Meas. Sci. Technol. 26, 074002-074011 (2015)

Yarlagadda, A., Yoganathan, A.: Experimental studies of model porous media fluid dynamics. Exp. Fluids 8(1-2), 59-71 (1989) 